\section{Scientific journal}

\section{PHYSICAL AND MATHEMATICAL EDUCATION}

Has been issued since 2013.

Науковий журнал

ФІЗИКО-МАТЕМАТИЧНА ОСВІТА

Видається з 2013.
ISSN 2413-158X (online)

ISSN 2413-1571 (print)

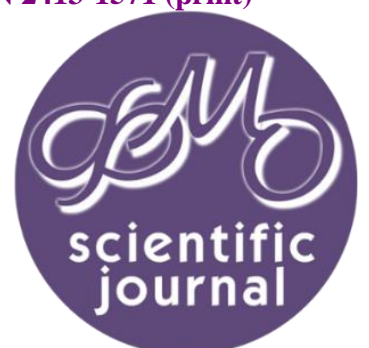

Івашина Ю.К., Ковальчук В.Т., Куриленко Н.В. Енергетичний підхід до описання процесів і розв'язування задач електрики. Фізико-математична освіта. 2021. Випуск 2(28). С. 46-50.

Ivashina Yu., Kovalchuk V., Kurylenko N. Energy approach to description of processes and solving electricity problems. Physical and Mathematical Education. 2021. Issue 2(28). P. 46-50.

DOI 10.31110/2413-1571-2021-028-2-008

удк 537.2/372.853

Ю.К. Івашина

Херсонський державний університет, Україна ivashinauriy@gmail.com

ORCID: 0000-0001-9569-2393

В.Т. Ковальчук

Приморська філія «Академічного лічею Скадовської міської ради», Україна

kovalchuk.v.t@gmail.com

Н.В. Куриленко

Херсонський державний університет, Україна Kurylenko.n.v1976@gmail.com ORCID: 0000-0002-1083-3247

\title{
ЕНЕРГЕТИЧНИЙ ПІДХІД ДО ОПИСАННЯ ПРОЦЕСІВ І РОЗВ'ЯЗУВАННЯ ЗАДАЧ ЕЛЕКТРИКИ
}

АНОТАЦІЯ

Формулювання проблеми. Завдяки універсальності закону збереження енергії енергетичний підхід можна застосовувати при описанні всіх фізичних процесів і розв'язуванні задач. Мета роботи - розкриття переваг та недоліків енергетичного підходу при описі фізичних прочесів і розв'язуванні задач електрики.

Матеріали і методи. Використано задачний метод: визначалася внутрішня сила, яка виникає в плоскому конденсаторі при зміні взаємного положення пластин на основі енергетичного і динамічного підходів, робота чієї сили і зміна енергії конденсатора для випадків його підключення і відключення від джерела струму.

Результати. Обгрунтовано природу різних сил, які діють всередині конденсатора. У випадку відключеного від джерела зарядженого конденсатора внутрішня сила-це пондемоторна сила притягування різнойменно заряджених пластин. При підключені конденсатора до джерела струму сила дії поля конденсатора має дві складові, які обумовлені зміною заряду і зміною ємності.

Висновки. Енергетичний підхід, як феноменологічний і макроскопічний, дозволяє достатньо просто визначати внутрішні сили, які діють в системі, їх роботу і зміну енергії системи, але не розкриває природу цих сил і механізм їх дії. застосування динамічного методу дозволяє не тільки визначити сили, що діють в системі, а й розкрити їх природу та механізм дії. Проте, такий підхід вимагає більш глибокого проникнення в суть фізичних явищ та процесів і його не завжди можна застосувати внаслідок неможливості, або складності визначення сили та їі залежності від змін в системі.

КлЮчОВІ словА: енергетичний підхід, переваги і недоліки, внутрішні сили в конденсаторі, зміна енергії.

ВСТУП

Постановка проблеми. Знання загальних методів описання фізичних процесів і розв'язування задач $є$ важливою умовою успішної підготовки кваліфікованого вчителя фізики. Одним із таких методів $є$ енергетичний підхід, основою якого $\epsilon$ найбільш загальний закон природи - закон збереження енергії. Фізика є природничою наукою, яка вивчає різні види руху матерії, універсальною мірою якого є енергія (Фейнман, Лейтон, Сендс, Т. 1. 2019). Поняття «енергія», закон збереження енергії відіграють важливу роль при викладанні фізики і мають суттєве методичне і практичне значення. Завдяки універсальності закону збереження енергії енергетичний підхід можна застосовувати при описанні всіх фізичних процесів і при розв'язуванні задач з усіх розділів фізики. Енергетичний підхід полягає в писанні процесів з точки зору зміни енергії тіл та систем, або перетворення ії в інші види. Мірою цих змін і перетворень $\epsilon$ робота. На жаль, в підручниках методичних посібниках він глибоко розроблений лише при розв'язуванні задач з механіки (Сивухин, 2005; Розіна, Бедрова, 2005). 
Енергетичний підхід крім переваг має і недоліки, тому використовуються і інші методи дослідження, що особливо яскраво виражено в термодинаміці, де термодинамічний (енергетичний ) спосіб опису термодинамічних систем доповнюється статистичним. В механіці також використовуються динамічний та енергетичний підходи до описання поведінки тіл і механічних систем та розв'язування задач.

Актуальність дослідження. Енергетичний підхід розглядався рядом вчених-методистів. Формуванням поняття «енергія», законом збереження енергії займалися А.Н. Малінін, В.В. Мултаноський, В.Ф. Савченко, А.В. Усова та інші вчені. Енергетичний підхід до розв'язування задач з фізики застосовувався В.І. Гутманом, А.Н. Малініним, Я.М. Гельфером, І.М. Гельфгафтом, І.Ю. Ненашевим, Л.А. Кіриком. Такий метод використовувався в механіці, термодинаміці, де він $\epsilon$ базовим, а також у квантовій, атомній і ядерній фізиці, де енергетичний підхід єєдино можливим (рівняння Ейнштейна для фотоефекту, енергія зв'язку ядра тощо). Енергетичний підхід широко використовується і в електриці. Визначення роботи електричного поля і струму, яка виражається через напругу, базується на ньому. Найбільш яскравим прикладом застосування енергетичного підходу в електриці є задача про визначення пондемоторних (механічних) сил, які виникають в плоскому конденсаторі при зміні відстані між пластинами, яка розглядалася в ряді робіт (Фейнман, Лейтон, Сендс, Т. 3. 2019; Тамм, 2003; Сивухин, 2004);

Переваги та недоліки енергетичного підходу на основі порівняння з іншими методами дослідження та розв'язання задач для електрики висвітлені недостатньо, тому тема роботи $є$ актуальною.

Мета статті - розкрити переваги та недоліки енергетичного підходу до описання процесів і розв'язування задач електрики на основі порівняння сил та їх роботи, які виникають в конденсаторі, енергетичним та динамічним методами.

\section{ТЕОРЕТИЧНІ ОСНОВИ ДОСЛІДЖЕННЯ}

Взаємодію тіл можна описати за допомогою сил, або за допомогою потенціальної енергії взаємодії, як функції координат тіл, що взаємодіють. Якщо відомі сили, що діють на тіла системи, то їі потенціальна енергія знаходиться шляхом інтегрування. Обернена задача - визначення сил по заданій потенціальній енергії - розв'язується за допомогою диференціювання (Сивухин, 2005). В електриці роль механічної потенціальної енергії відіграє енергія електричного поля.

Для опису механічних систем використовується як динамічний, так і енергетичний методи. Чим складніша система, тим енергетичний підхід стає більш оптимальним. Можливості енергетичного підходу розширюються завдяки введенню Лагранжем зв'язку узагальненої сили $\Lambda_{\mathrm{i}}$ та відповідної їй узагальненої координати $\lambda_{\mathrm{i}}$.

$$
\Lambda_{i}=-\frac{\partial W}{\partial \lambda_{i}}
$$

де W - енергія системи. В якості узагальненої сили може бути не тільки класична динамічна сила, а і тиск газу, коефіцієнт поверхневого натягу, обертовий момент, що діє на електричний диполь в електричному полі, напруженість електричного поля в діалектриках тощо (Базаров, 2010).

Загальний метод знаходження пондемоторних сил, абстрагуючись від причин їх виникнення, дає термодинаміка. В (Сивухин, 2004) таку задачу для плоского конденсатора розв'язано через вільну енергію системи і їі зміну при віртуальному зміщенні в системі. Введення таких зміщень розглядається як штучний прийом для визначення діючих в системі сил.

Фейнман (Фейнман, Лейтон , Сендс, Т.3. 2019) для визначення сили F, що діє на пластини плоского конденсатора, використав принцип віртуальної роботи, який витікає із (1).

$$
\Delta W=F \cdot \Delta x
$$

де $\Delta x$ - віртуальне (мале) зміщення пластини, $\Delta W$ - зміна енергії конденсатора внаслідок зміщення пластини на $\Delta x$. Такий спрощений підхід дозволяє використовувати вказаний принцип без використання частинних похідних. Але приріст енергії конденсатора необхідно визначати за правилами диференціального числення. Так, коли $q=$ const $\mathbf{W}=\frac{\mathbf{q}^{2}}{2 \mathrm{C}}$

$$
\Delta W=\frac{q^{2}}{2} \Delta\left(\frac{1}{C}\right)=-\frac{\mathrm{q}^{2}}{2 C^{2}} \Delta C
$$

Слід відмітити, що визначення сил на основі (1) справедливе для консервативних систем, в яких відсутні сили опору. Наявність таких сил при водить до того, що частина енергії системи розсіюється.

\section{МЕТОДИ ДОСЛІДЖЕННЯ}

Використано задачний метод: визначалася внутрішня сила, яка виникає в плоскому конденсаторі при зміні взаємного положення пластин на основі енергетичного і динамічного підходів, робота цієї сили і зміна енергії конденсатора для випадків його підключення і відключення від джерела струму.

\section{РЕЗУЛЬТАТИ ДОСЛІДЖЕННЯ ТА ЇХ ОБГОВОРЕННЯ}

а) Конденсатор заряджено і відключено від джерела.

В цьому випадку $q$ = const $\mathrm{i}$ енергія конденсатора визначається

$$
W=\frac{q^{2}}{2 C}=\frac{q^{2} x}{2 \varepsilon_{0} S},
$$

де $x$ - відстань між пластинами. Із (1) і (4) сила взаємодії між пластинами

$$
F_{x}=-\frac{\partial W}{\partial x}=-\frac{q^{2}}{2 \varepsilon_{0} S}=-\frac{\sigma^{2} S}{2 \varepsilon_{0}},
$$


де $\sigma$ - поверхнева густина заряду на пластинах. Знак мінус показує, що сила Fx направлена в сторону зменшення відстані, тобто це сила притягування. Під дією внутрішньої сили система прямує до зменшення енергії.

Визначимо цю силу на основі динамічного підходу. Поле між пластинами однорідне. Одна пластина знаходиться

в полі іншої $E=\frac{\sigma}{2 \varepsilon_{0}}$. Різнойменно заряджені пластини притягуються із силою

$$
F_{x_{1}}=\int_{S} d F_{x}=\int_{S} \frac{\sigma}{2 \varepsilon_{0}}(-\sigma) d S=-\frac{\sigma^{2} S}{2 \varepsilon_{0}},
$$

Вирази (5) і (6) співпадають. Але сила, отримана на основі енергетичного підходу, визначається простіше. Особливо наглядно це проявляється при інших способах зміни ємності. При зсуві пластин, витягуванні діелектричної пластини, повороті пластин тангенціальні складові сил взаємодії між обкладинками і між ними та діелектричною пластиною на основі динамічного підходу визначити дуже складно із-за нерівномірного розподілу заряду на обкладинках i поляризаційного заряду діелектричної пластини.

Продемонструємо це на прикладі зсуву пластин конденсатора зарядженого і відключеного від джерела. Розглянемо тангенціальну складову сили взаємодії між пластинами конденсатора $F_{y}$, яка виникає при їх зсуві.

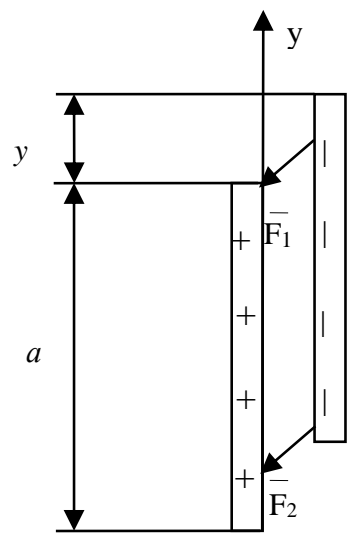

Рис. 1. Сили, що діють при зсуві пластин конденсатора

У цьому випадку крім сили притягування різнойменних пластин $F_{x}$ виникає тангенціальна складова сил $F_{1}$ i $F_{2}$, які діють на неперекриті ділянки пластини і намагаються ліквідувати зсув. Визначити ці сили шляхом інтегрування сил взаємодії між окремими ділянками зсунутих частин пластин дуже складно внаслідок нерівномірного розподілу заряду і неоднорідності поля. Але це легко зробити на основі енергетичного підходу. Енергія конденсатора:

$$
W=\frac{q^{2}}{2 C}=\frac{q^{2} x}{2 \varepsilon_{0}(a-y) b}
$$

де $а$ i b- розміри пластини, $y$-величина зсуву.

$$
F_{y}=-\frac{\partial W}{\partial y}=-\frac{q^{2} x}{2 \varepsilon_{0}(a-y)^{2} b}
$$

Із (8) слідує, що сила $F_{y}$ протидіє зсуву і залежить від у і величини заряду. Визначимо роботу сили взаємодії пластин при їх зближенні на основі (6).

$$
A_{1-2}=F_{x_{1}}\left(x_{2}-x_{1}\right)=\frac{\sigma^{2} S}{2 \varepsilon_{0}}\left(x_{1}-x_{2}\right)=\frac{q^{2}}{2 \varepsilon_{0} S}\left(x_{1}-x_{2}\right)
$$

На основі енергетичного підходу робота внутрішньої сили системи

$$
A_{1-2}=W_{1}-W_{2}
$$

Результати еквівалентні, але на основі енергетичного підходу роботу можна визначити простіше. Під дією внутрішньої сили система прямує до зменшення енергії. Пояснимо куди перейшла частина енергії конденсатора. Вона рівна енергії його електричного поля. При зближенні пластин при $q=$ const густина енергії поля не змінюється і зменшення об'єму поля приводить до зменшення енергії конденсатора. Пластини конденсатора утримуються від зближення зовнішніми силами, які виникають в жорсткій механічній конструкції, яка закріплює пластини. При їх зближенні робота зовнішніх сил буде від'ємною, що викликає зменшення енергії конденсатора. Робота внутрішньої сили $F_{x}$ при цьому буде додатною. Можливий випадок, коли пластини утримуються силами пружності діелектричної пластини. При зближенні обкладинок частина електричної енергії перейде в енергію пружної деформації діелектрика.

б) Конденсатор підключено до джерела струму.

В цьому випадку виконується умова $U=$ const і енергія конденсатора визначається

$$
W=\frac{C U^{2}}{2}=\frac{\varepsilon_{0} S U^{2}}{2 x}
$$

Внутрішня сила на основі (1) 


$$
F_{x_{2}}=-\frac{d W}{d x}=\frac{\varepsilon_{0} S U^{2}}{2 x^{2}}=\frac{C U^{2}}{2 x}
$$

При зближенні пластин енергія конденсатора збільшується, а внутрішня сила протидіє зближенню. Це обумовлено тим, що на конденсатор діють зовнішні сили - джерело струму, тому заряд конденсатора змінюється.

$$
F_{x_{2}}=-\frac{\partial W}{\partial x}=-\left(\frac{\partial W}{\partial q} \cdot \frac{\partial q}{\partial x}+\frac{\partial W}{\partial C} \cdot \frac{\partial C}{\partial x}\right)
$$

врахуємо, що $q=C U=\frac{\varepsilon_{0} \mathrm{~S}}{x} U, C=\frac{\varepsilon_{0} S}{x}$ тоді

$$
F_{x_{2}}=\frac{\varepsilon_{0} S U^{2}}{x^{2}}-\frac{\varepsilon_{0} S U^{2}}{2 x^{2}}=\frac{\varepsilon_{0} S U^{2}}{2 x^{2}}
$$

Внутрішня сила (сила дії поля конденсатора) має дві складові, які обумовлені зміною заряду і зміною ємності. Пояснимо природу цих сил з допомогою динамічного підходу. Друга складова сили $F_{x_{2}}$

$$
F_{x_{2}}^{\prime \prime}=-\frac{\varepsilon_{0} S U^{2}}{2 x^{2}}=-\frac{\sigma^{2} S}{2 \varepsilon_{0}}=F_{x_{1}}
$$

співпадає із (5) і визначає пондемоторну силу притягування пластин, робота якої (15) при зближені додатна і проводить до зменшення енергії конденсатора.

$$
A\left(F^{\prime \prime} x_{2}\right)=\int_{x 1}^{x_{2}} F_{x_{2}}^{\prime \prime} d x=\frac{\varepsilon_{0} S U^{2}}{2}\left(\frac{1}{x_{2}}-\frac{1}{x_{1}}\right)>0
$$

Елементарна робота джерела струму при зміні заряду конденсатора

$$
d A_{\partial \varkappa}=\mathrm{Udq}
$$

де $d q=U d C=-U \varepsilon_{0} S \frac{d x}{x^{2}}$

Робота джерела струму по підзарядці конденсатора при зближенні пластин

$$
A_{\partial \varkappa}=\varepsilon_{0} S U^{2} \int_{x 1}^{x_{2}} \frac{d x}{x^{2}}=\varepsilon_{0} S U^{2}\left(\frac{1}{x_{2}}-\frac{1}{x_{1}}\right)>0
$$

Робота сил електричного поля конденсатора проти зовнішньої сили (джерела) має протилежний знак. Ця робота від'ємна і вдвічі більша роботи пондемоторної сили (15), що обумовлює від'ємний знак сумарної роботи сил поля і, відповідно, збільшення енергії конденсатора при зближені пластин за умови $U$ = const.

При застосуванні енергетичного підходу необхідно враховувати дію як внутрішніх, так і зовнішніх потенціальних сил на енергію системи. Це наочно демонструє приклад конденсатора, підключеного до джерела струму. Впливають на енергію системи і дисипативні сили опору, дія яких приводить до дисипації частини механічної енергії. В електричних системах енергія розсіюється на активному опорі, прикладом чого $є$ затухання вільних коливань в реальному контурі (Сивухин, 2004).

\section{ВИСНОВКИ ТА ПЕРСПЕКТИВИ ПОДАЛЬШИХ ДОСЛІДЖЕНЬ}

Енергетичний підхід до описання процесів і розв'язування задач знайшов своє застосування в усіх розділах фізики завдяки своїй важливості та універсальності.

Для розкриття переваг і недоліків енергетичного підходу в електриці було визначено внутрішні сили і їх роботу, які виникають при зміні ємності конденсатора за допомогою енергетичного та динамічного методів. Розглянуто випадки підключеного до джерела струму конденсатора і зарядженого та відключеного.

Порівняння отриманих результатів дозволило зробити наступні висновки:

1. Енергетичний підхід, як феноменологічний і макроскопічний, дозволяє достатньо просто визначати внутрішні сили, що діють в системі, їх роботу і зміну енергії системи, але не розкриває природу цих сил і механізм їх дії.

2. Застосування динамічного методу дозволяє не тільки визначити сили, що діють в системі, а і розкрити їх природу та механізм дії. Але такий підхід вимагає більш глибокого проникнення в суть фізичних явищ та процесів і його не завжди можна застосувати внаслідок неможливості, або складності визначення сили та їі залежності від змін в системі.

3. При застосуванні енергетичного підходу необхідно враховувати дію не тільки внутрішніх і зовнішніх потенціальних сил, а й наявність механічного та електричного опорів, які приводять до дисипації частини енергії системи.

4. Енергетичний та динамічний підходи доповнюють один одного і дозволяють оптимальним чином описати процеси або розв'язати задачі в залежності від проблем, які необхідно розкрити.

В подальшому ми плануємо за допомогою енергетичного підходу визначити пондемоторні сили, які виникають при переміщенні осердя соленоїдів.

\section{Список використаних джерел}

1. Базаров И.П. Термодинамика: Учебник. 5-е изд., стер. СПб.: Издательство «Лань», 2010. 384 с.

2. Розіна О., Бедрова О. Використання закону збереження енергії для розв'язування задач механіки. Фізика та астрономія в школі. 2005. №3. С. 35-40.

3. Сивухин Д.В. Общий курс физики. Том III. Электричество. 4-е изд., стереот. М.: ФИЗМАТЛИТ; Изд-во МФТИ, 2004. 656с.

4. Сивухин Д.В. Общий курс физики. Механика. 4-е изд., Стереот. М.: ФИЗМАТЛИТ; Изд-во МФТИ, 2005. 560 с. 
5. Тамм И. Е. Основы теории электричества: Учеб. пособие для вузов. 11-е изд испр. и доп. М.: ФИЗМАТлИТ, 2003. 616 с. URL: http://bamper.info/568-tamm_i_e_osnovy_teorii_elektricestva_uceb_poso.html

6. Фейнман Р., Лейтон Р., Сендс М. Электричество и магнетизм. Москва: АСТ, 2019. Т. 3. 304 с. (Феймановские лекции по физике).

7. Фейнман Р., Лейтон Р., Сендс М. Современная наука о природе. Законы механики. Пространство. Время. Движение. Москва: АСТ, 2019. Т. 1. 478 с. (Феймановские лекции по физике).

\title{
References
}

1. Bazarov I.P. (2010). Termodinamika [Thermodynamics]: Textbook. 5th ed., Erased. SPb .: Publishing house «Lan» [in Russian].

2. Rozina O., Bedrova O. (2005). Vikoristannja zakonu zberezhennja energiï dlja rozv'jazuvannja zadach mehaniki [Using the law of conservation of energy to solve problems of mechanics] Physics and astronomy at school. issue №3, 35-40 [in Ukraine].

3. Sivuhin D.V. (2004) Obshhij kurs fiziki [General physics course]. Volume III. Electricity. 4th ed., Stereo. M.: FIZMATLIT; Publishing house of MIPT [in Russian].

4. Sivuhin D.V. (2005). Obshhij kurs fiziki [General physics course]. Mechanics. 4th ed., Stereot. M .: FIZMATLIT; Publishing house of MIPT [in Russian].

5. Tamm I. E. (2003). Osnovy teorii jelektrichestva [Basic theory of electricity]: Textbook. manual for universities. 11th ed. Rev. and add. M .: FIZMATLIT [in Russian].

6. Richard Feynman, Robert Leighton, Matthew Sands. (2019) Jelektrichestvo i magnetizm [Electricity and magnetism]. Vol. 3. Moscow: AST (Feynman Lectures in Physics) [in Russian].

7. Richard Feynman, Robert Leighton, Matthew Sands. (2019). Sovremennaja nauka o prirode. Zakony mehaniki. Prostranstvo. Vremja. Dvizhenie. [Modern science of nature. The laws of mechanics. Space. Time. Traffic]. Vol. 1. Moscow: AST (Feynman Lectures in Physics) [in Russian].

\section{ENERGY APPROACH TO DESCRIPTION OF PROCESSES AND SOLVING ELECTRICITY PROBLEMS}

\author{
Yu.K. Ivashina
}

Kherson State University, Ukraine

V.T. Kovalchuk

Primorsky branch of the Academic Lyceum of Skadovsk City Council, Ukraine

N.V. Kurylenko

Kherson State University, Ukraine

Abstract.

Formulation of the problem. Due to the universality of the law of conservation of energy, the energy approach can be used to describe all physical processes and solve problems. The energy approach has advantages and disadvantages. The purpose of the work is to reveal the advantages and disadvantages of the energy approach to describing the processes and solving problems of electricity.

Materials and methods. The internal force that occurs in a flat capacitor when changing the relative position of the plates based on energy and dynamic approaches, the operation of this force and the change in energy of the capacitor for cases of its connection and disconnection from the current source were determined.

Results. In the case of a disconnected charged capacitor from the source, the internal force is the pondemotor force of attraction of differently charged plates. When the capacitor is connected to a current source, the field strength of the capacitor has two components, which are due to a change in charge and a change in capacity. The nature of these forces is explained on the basis of a dynamic approach.

Conclusions. The energy approach, both phenomenological and macroscopic, allows you to easily determine the internal forces acting in the system, their work and change the energy of the system, but does not reveal the nature of these forces and the mechanism of their action. The application of the dynamic method allows not only to determine the forces acting in the system, but also to reveal their nature and mechanism of action. But this approach requires a deeper insight into the essence of physical phenomena and processes and it can not always be applied due to the impossibility or difficulty of determining the force and its dependence on changes in the system.

Keywords: energy approach, advantages and disadvantages, internal forces in the capacitor, energy change.

\section{$(C c)$ BY-NC-SA}

This work is licensed under Creative Commons Attribution-NonCommercial-ShareAlike 4.0 International License. 